\title{
A community based assessment study of positioning, attachment and suckling during breastfeeding among 0-6 months aged infants in rural area of Gandhinagar district, Gujarat, India
}

\section{Arpit Chelabhai Prajapati*, Haresh Chandwani, Bhavik Rana, Kantibhai N. Sonaliya}

Department of Community Medicine, GCS Medical College, Hospital and Research Center, Ahmedabad, Gujarat, India

Received: 24 May 2016

Accepted: 13 June 2016

*Correspondence:

Dr. Arpit Chelabhai Prajapati,

E-mail: arpit4frds@yahoo.co.in

Copyright: () the author(s), publisher and licensee Medip Academy. This is an open-access article distributed under the terms of the Creative Commons Attribution Non-Commercial License, which permits unrestricted non-commercial use, distribution, and reproduction in any medium, provided the original work is properly cited.

\begin{abstract}
Background: Effective breastfeeding is a function of the proper positioning of mother and baby and attachment of child to the mother's breast. Integrated Management of Neonatal and Childhood Illness (IMNCI) strategy recommended systematic assessment of breastfeeding and emphasized counselling of the mother on proper positioning and attachment of infant to the breast. Objective of the study was to assess the correct position, attachment and effective suckling in the breastfeeding of infants as practiced by mothers in rural community.

Methods: An observational, descriptive study was done at field practice area of rural health training centre, Dabhoda, from January 2013 to December 2013. One hundred twenty mothers of 0-6 months of aged infant were interviewed and observed for baby's position, attachment and effective suckling using pre-tested semi-structured questionnaire through random selection. Grading of positioning, attachment and suckling was done according to the score of various characteristics. Data thus collected were analyzed using MS Excel 2007 and also Epi info.

Results: There was poorer positioning among primipara $(41.7 \%)$ than multipara $(20.9 \%)$ mothers. Poorer attachment was also more evident among primipara (45.8\%) compared to multipara (10.9\%) mothers. Parity was significantly linked with poor positioning of infant $(\mathrm{P}$ value $=0.001)$ and attachment $(\mathrm{P}$ value $<0.001)$. Maternal occupation was also significantly associated with attachment ( $\mathrm{p}$ value $=0.028)$ and positioning $(\mathrm{p}$ value $=0.009)$. Preterm delivery was significantly associated with poor attachment $(\mathrm{P}$ value $=0.023)$ and poor effective suckling $(\mathrm{P}$ value $<0.0001)$.

Conclusions: Primipara mothers require help and support for correct breastfeeding techniques as poor positioning and attachment was found among primipara mothers.
\end{abstract}

Keywords: Attachment, Breastfeeding, Effective suckling, Positioning

\section{INTRODUCTION}

Under any situation, breast milk is the best food for the infant. Breast milk provides the main source of food in the first year of life. ${ }^{1}$

Current knowledge and expertise has not been able to manufacture a superior food for young infants than mother's milk. Breast feeding is the best way to satisfy the nutritional and psychological needs of the baby. ${ }^{2}$
Breastfeeding confers short-term and long-term benefits on both child and mother, including helping to protect children against a variety of acute and chronic disorders. The review of studies from developing countries shows that infants who are not breastfed are 6-10 times more likely to die in the first few months of life than infants who are breastfed. Diarrhea and pneumonia are more common and more severe in children who are artificially fed, and are responsible for many of these deaths. 
Positive effects of breastfeeding on the wellbeing of infants and mothers are observed in every condition. Breast-feeding reduces the risk of acute infections such as diarrhoea, pneumonia, ear infection, Haemophilus influenza, meningitis and urinary tract infection. ${ }^{3}$

Artificially fed children have an increased risk of long term diseases with an immunological basis, including asthma and other atopic conditions, type 1 diabetes, celiac disease, ulcerative colitis and Crohn's disease. ${ }^{3}$

Improving maternal knowledge, feeding, and time for care during pregnancy(to address low birth weight, especially in South Asia) and lactation and improving infant feeding and caring practices, such as exclusive breastfeeding and adequate and timely complementary feeding, are critical to improving nutrition outcomes. These tasks are closely linked to issues of gender. ${ }^{4}$

Based on evidence of the effectiveness of interventions, achievement of universal coverage of optimal breastfeeding could prevent $13 \%$ of deaths occurring in children less than 5 years of age worldwide, while appropriate complementary feeding practices would result in a further $6 \%$ reduction in under-five mortality. ${ }^{5}$ Suckling with poor attachment may be uncomfortable or painful for the mother, and may damage the skin of the nipple and areola, causing sore nipples and fissures (or "cracks"). Poor attachment is the commonest and most significant cause of sore nipples, and may result in inefficient removal of milk and apparent low supply. ${ }^{6}$

There are several reasons that an infant may be poorly attached or not able to suckle effectively. He may have had bottle feeds, especially in the first few days after delivery. His mother may be inexperienced. She may have had some difficulty and nobody to help or counsel her. The infant may be poorly positioned at the breast. Positioning is vital because poor positioning often results in poor attachment, especially in younger infants. If the infant is positioned well, the attachment is likely to be good. ${ }^{7}$

Prolonged, frequent feeds can be a sign of ineffective suckling and inefficient transfer of milk to the child. This is usually due to poor attachment, which may also lead to sore nipples. If the attachment is improved, transfer of milk becomes more efficient, and the feeds may become shorter or less frequent. At the same time, the risk of nipple damage is reduced. ${ }^{6}$

Effective breastfeeding is a function of the proper positioning of mother and baby and attachment of child to the mother's breast. ${ }^{8}$

Positioning of the baby's body is important for good attachment and successful breastfeeding. Most difficulties can be avoided altogether if good attachment and positioning are achieved at the first and early feeds. Most difficulties with breastfeeding are due to restricted feeding time, lack of confidence or poor attachment of the baby at the breast. End result of restricted feeding is engorgement which in turn can direct to poor attachment. Good attachment and unobstructed breastfeeding prevents engorgement, blocked milk ducts and mastitis.9 The importance of correct fixing and positioning of the baby on the breast is considered as a prime requisite for reducing trauma, and hence the occurrence of sore nipples, thus practical recommendations are given for achieving optimal attachment of the baby at the breast. ${ }^{10}$ An effective sucking technique is considered important to establish breastfeeding, to ensure milk transfer, and to prevent breastfeeding problems. ${ }^{8,11,12}$

$33 \%$ of the mother-baby pairs were having problems latching or sucking on discharge from hospital (fourth to fifth post-partum days). ${ }^{13}$

The baby's positioning and attachment to the breast during breastfeeding are fundamental toward the occurrence of different sorts of nipple trauma.

Integrated Management of Neonatal and Childhood Illness (IMNCI) strategy recommended systematic assessment of breastfeeding and emphasized counselling of the mother on proper positioning and attachment of infant to the breast.

After review of literature it was found that, there is less comparable documented study conducted in Gujarat on breastfeeding positioning of baby, baby's attachment to breast and effective sucking. This study was, therefore, conducted with the objective of assessing the correct position, attachment and effective suckling in infant breastfeeding as practiced by mothers residing in rural area of Gandhinagar district.

\section{METHODS}

This observational descriptive study was conducted at field practice area of Rural Health Training Centre of GCS Medical College from January 2013 to December 2013. One hundred twenty mothers were interviewed and observed for mother and baby's position, infant's mouth attachment and effective suckling during breastfeeding using pre-tested questionnaire during the study period through random selection. Informed verbal consent was obtained before data collection.

ASHA workers were trained by the investigators to collect data and observe the positions of baby, infant's mouth attachment to breast and effective suckling by using video clips, posters and hands on training and demonstration. The information on the maternal characteristics like age, occupation, parity and baby's age, preterm/full term, birth weight was obtained using predesigned and pre-tested questionnaire.

ASHA worker observed the breastfeeding process for 5 minutes and recorded the mother and infant's positioning, attachment to the breast and effective suckling as per 
observation form. Observation was done by asking the mother to put her infant to the breast if possible. If the infant had been fed during the last 1 hour, then the mother was asked when the infant would have the next feed and the observation assessment was planned accordingly.

The following grading system to grade positioning and infant's mouth attachment and effective suckling during breastfeeding based on IYCF criteria was adopted.

\section{Criteria for correct body position}

1. Baby neck straight or slightly bent slightly back and body straight

2. Baby body turned towards mother

3. Baby body close to mother body and face to breast

4. Baby whole body supported

\section{Criteria for correct attachment of baby}

1. Chin touching breast

2. Mouth wide and open

3. Lower lip turned outward

4. More areola seen above baby mouth

\section{Criteria for correct effective suckling}

1. Slow sucks

2. Deep sucks

3. Sometime pausing

Grading system for infant's mouth attachment and effective suckling during breastfeeding.

\begin{tabular}{|ll|}
\hline Correct body position & Grade \\
\hline One criteria from infant's position & Poor \\
\hline Any two criteria from infant position & Average \\
\hline Any three criteria or all criteria & Good \\
\hline Correctness of attachment & Grade \\
\hline Any one of four criteria & Poor \\
\hline Any two of four criteria & Average \\
\hline Any three or all criteria & Good \\
\hline Correctness of effective suckling & Grade \\
\hline Any one of three criteria & Poor \\
\hline Any two or all the three criteria & Good \\
\hline
\end{tabular}

The data were analyzed using MS Excel 2007 and Epi info 7. Chi-squared test was used as test of significance.

\section{RESULTS}

\section{Maternal characteristics}

In table 1, present study shows majority of the mothers were $>=25$ years of age $(68.3 \%)$ and others remaining $31.7 \%$ were $<25$ years of age. Poor position $(22.2 \%)$ and poor attachment $(33.3 \%)$ were high among mothers aged less than 25 years as compared to $>=25$ years of age groups. However, there was no statistically significant association between the mother's age and poor position ( $\mathrm{P}$ value $=0.102)$ and attachment $(P$ value $=0.842)$ of babies to the breast during feeding.

The majority of mothers were multipara $(80 \%)$ and $20 \%$ were primipara. Among mothers with primipara higher percentages of poor position $(41.7 \%)$ and attachment $(45.8 \%)$ were observed. A statistically significant association was found between parity and position ( $\mathrm{P}$ value $=0.001)$ and attachment $(\mathrm{P}$ value $<0.001)($ Table 1).

$74.2 \%$ mothers were housewife (non working) while $25.8 \%$ were working mothers. Although there was poorer positioning among working (22.6\%) than working mothers $(13.5 \%)$, poor attachment was more in working $(22.6 \%)$ than nonworking $(11.2 \%)$ mothers. Maternal occupation and position $(\mathrm{P}$ value $=0.028)$ and attachment ( $\mathrm{P}$ value $=0.009)$ was significantly associated statistically (Table 1).

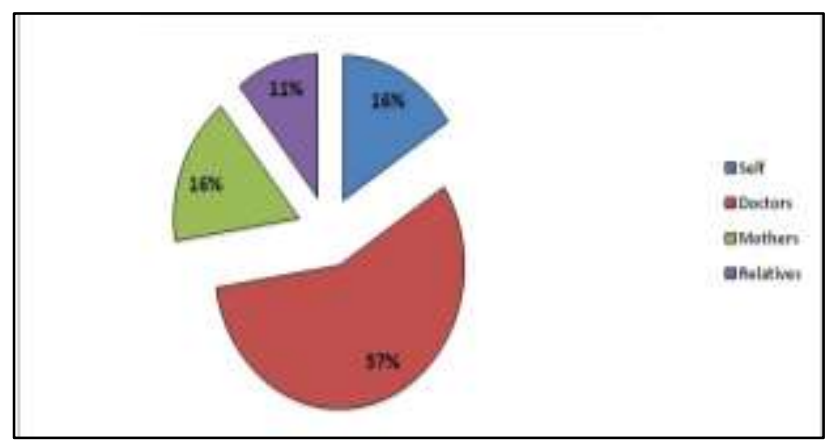

Figure 1: Source of information of correct breast feeding technique.

\section{Infant characteristics}

All infants were observed for attachment to the breast and effective suckling

In Table 2, most of the neonates were full term $(87.5 \%)$ and only $12.5 \%$ were preterm. Only $11.4 \%$ of total fullterm babies had poorer attachment as compared to preterm babies (33.3\%). Poor suckling were found $7.6 \%$ among full-term babies and $66.7 \%$ in preterm babies. These findings were statistically significant for attachment $(\mathrm{P}$ value $=0.023)$ and effective suckling $(\mathrm{P}$ value $<0.0001)$.

Only $20(16.7 \%)$ babies had birth weight less of than 2.5 $\mathrm{kg}$ (low birth weight as per WHO for developing countries) and the remaining $83.3 \%$ babies weighed more than $2.5 \mathrm{~kg}$. Poor attachment $(30 \%)$ and poor suckling $(40 \%)$ were more in babies with low birth weight as compared to other group that is babies with $2.5 \mathrm{~kg}$ or more birth weight (11\% and $10 \%$ respectively). 
There was no statistically significant difference found between the birth weight of infant and attachment $(\mathrm{P}$ value $=0.146)$ to the breast, but statistically significant difference was observed for effective suckling $(\mathrm{P}$ value $=$ 0.001).
In present study figure 1 shows most important source of information regarding breast feeding technique was doctors $(57 \%)$ followed by mothers (16\%).

Table 1: Maternal characteristics and position of mother and infant and attachment (latch-on) to breast during feeding.

\begin{tabular}{|c|c|c|c|c|c|c|}
\hline \multirow[t]{3}{*}{ Characteristic } & \multicolumn{6}{|c|}{ Grade } \\
\hline & \multicolumn{3}{|c|}{ Position grade } & \multicolumn{3}{|c|}{ Attachment grade } \\
\hline & $\begin{array}{l}\text { Poor No. } \\
(\%)\end{array}$ & $\begin{array}{l}\text { Average No. } \\
(\%)\end{array}$ & $\begin{array}{l}\text { Good No. } \\
(\%)\end{array}$ & Poor No. $(\%)$ & $\begin{array}{l}\text { Average No. } \\
(\%)\end{array}$ & Good No. (\%) \\
\hline \multicolumn{7}{|c|}{ Maternal age (in years) } \\
\hline$<25(\mathrm{n}=38)$ & $08(21.1)$ & 09 (23.6) & $21(55.3)$ & 07 (18.4) & $08(21.1)$ & $23(60.5)$ \\
\hline$>=25(n=82)$ & $11(13.4)$ & $28(34.1)$ & $43(52.4)$ & $10(12.2)$ & $23(28.1)$ & $49(59.7)$ \\
\hline Total $(n=120)$ & \multicolumn{3}{|c|}{$\mathrm{X}^{2}=7.729, \mathrm{p}$ value $=0.102$} & \multicolumn{3}{|c|}{$\mathrm{X}^{2} 1.415, \mathrm{p}$ value $=0.842$} \\
\hline \multicolumn{7}{|l|}{ Parity } \\
\hline $1(\mathrm{n}=24)$ & $10(41.7)$ & $09(37.5)$ & $5(20.8)$ & $11(45.8)$ & $06(25)$ & $07(29.2)$ \\
\hline $2-4(n=66)$ & $05(7.6)$ & $20(30.3)$ & $41(62.1)$ & $05(7.6)$ & $13(19.7)$ & $48(72.7)$ \\
\hline$>4(\mathrm{n}=30)$ & $04(13.3)$ & $08(26.7)$ & $18(60)$ & $01(3.3)$ & $12(40)$ & $17(56.7)$ \\
\hline Total $(n=120)$ & \multicolumn{3}{|c|}{$\mathrm{X}^{2}=33.242, \mathrm{p}$ value $=0.001^{*}$} & \multicolumn{3}{|c|}{$\mathrm{X}^{2} 35.902, \mathrm{p}$ value $=<0.001^{*}$} \\
\hline \multicolumn{7}{|l|}{ Maternal occupation } \\
\hline Working $(n=31)$ & 07 (22.6) & $10(32.3)$ & $14(45.1)$ & 07 (22.6) & $13(41.9)$ & $11(35.5)$ \\
\hline Housewife $(n=89)$ & $12(13.5)$ & $27(30.3)$ & $50(56.2)$ & $10(11.2)$ & $18(20.2)$ & $61(68.6)$ \\
\hline Total $(\mathrm{n}=120)$ & \multicolumn{3}{|c|}{$\mathrm{X}^{2}=10.886, \mathrm{p}$ value $0.028^{*}$} & \multicolumn{3}{|c|}{$X^{2}=13.618, p$ value $=0.009^{*}$} \\
\hline \multicolumn{7}{|l|}{ Maternal Education } \\
\hline Illiterate $(\mathrm{n}=37)$ & $04(10.8)$ & $12(32.4)$ & $21(56.8)$ & $01(2.7)$ & $14(37.8)$ & $22(59.5)$ \\
\hline $\begin{array}{l}\text { Primary schooling or } \\
\text { higher }(n=83)\end{array}$ & $15(18.1)$ & $25(30.1)$ & $43(51.8)$ & $16(19.3)$ & $17(20.5)$ & $50(60.2)$ \\
\hline Total $(n=120)$ & \multirow{2}{*}{\multicolumn{3}{|c|}{$X^{2}=14.155, p$ value $=0.078$}} & \multirow{2}{*}{\multicolumn{3}{|c|}{$X^{2}=16.229, p$ value $=0.039^{*}$}} \\
\hline $\mathrm{N}=$ number of infant & & & & & & \\
\hline
\end{tabular}

Table 2: Attachment (latch-on) and effective suckling as per infant characteristics.

\begin{tabular}{|c|c|c|c|c|c|}
\hline \multirow{3}{*}{ Characteristic } & \multicolumn{5}{|l|}{ Grade } \\
\hline & \multicolumn{3}{|l|}{ Attachment } & \multicolumn{2}{|c|}{ Effective suckling } \\
\hline & Poor No. $(\%)$ & $\begin{array}{l}\text { Average No. } \\
(\%)\end{array}$ & Good No. (\%) & Poor No. (\%) & Good No. (\%) \\
\hline \multicolumn{6}{|l|}{ Gestation } \\
\hline Pre term $(n=15)$ & $05(33.3)$ & $05(33.3)$ & $05(33.4)$ & $10(66.7)$ & $05(33.3)$ \\
\hline Full term $(n=105)$ & $12(11.4)$ & $26(24.8)$ & $67(63.8)$ & $08(7.6)$ & $97(92.4)$ \\
\hline Total $(\mathrm{n}=120)$ & \multicolumn{3}{|c|}{$\mathrm{X}^{2}=11.368, \mathrm{p}$ value $=0.023^{*}$} & \multicolumn{2}{|c|}{$\mathrm{X}^{2}=35.892, \mathrm{p}$ value $=<0.0001 *$} \\
\hline \multicolumn{6}{|l|}{ Birth weight } \\
\hline$<2.5 \mathrm{~kg}(\mathrm{n}=20)$ & $06(30)$ & $06(30)$ & $08(40)$ & $08(40)$ & $12(60)$ \\
\hline$>=2.5 \mathrm{~kg}(\mathrm{n}=100)$ & $11(11)$ & $25(25)$ & $64(64)$ & $10(10)$ & $90(90)$ \\
\hline Total $(n=120)$ & \multicolumn{3}{|c|}{$\mathrm{X}^{2}=6.823, \mathrm{p}$ value $=0.146$} & \multicolumn{2}{|c|}{$\mathrm{X}^{2}=11.765, \mathrm{p}$ value $=0.001 *$} \\
\hline
\end{tabular}

\section{DISCUSSION}

In the present study, poorer attachment was observed in young mothers ( $<25$ years of age) as compared to older mothers, which is necessary for effective breastfeeding.
Such studies were also done by Hanne Kronborg et al and Gupta et al (North India). ${ }^{14,15}$

Santo et al from Porto Alegre, Brazil also reported that poor attachment technique was associated with early termination of exclusive breast feeding. ${ }^{16}$ 
'Good attachment' was observed amongst $42 \%$ infants and $60 \%$ mothers held infant in 'correct position' in study carried out by Sai et al in North India ${ }^{17}$

Rasha Mohamed Essa et al found about and more than two- thirds $(73.7 \%$ and $63.7 \%$ ) of respondent had poor body position and poor attachment grade respectively. While no one of them $(0.0 \%$ and $0.0 \%)$ had either good body position or attachment grade. ${ }^{18}$

Inappropriate breastfeeding position and attachment were the major problems (12 to $15 \%$ ). A study by Mannan I et al. found $74 \%$ infants were in correct breastfeeding position while good attachment was found in $72.3 \%$ infants. $^{19}$

Subhash B Thakre et al. observed that during breast feeding chin touching to the breast in $51.92 \%$ infant, lower lip turned outward in $36.54 \%$ infant, baby's mouth is widely open in $58.65 \%$ infant, more areola visible above than below in $26.92 \%$ infant. Poor positioning of breast and poor attachment were documented at 24 hours after birth. ${ }^{20}$

Madhu Gupta et al found in North India only $9.7 \%$ had correct attachment technique and $0 \%$ had correct positioning technique and also observed $45.2 \%$ Child had deep and well suckling reflex. ${ }^{15}$ Prabha Shrivastava et al reported $41.2 \%$ babies were well attached and $47.4 \%$ babies were correctly positioned in their study conducted in west Bengal. ${ }^{21}$ Mamta Parashar et al. found correct attachment and positioning was in $7.5 \%$ of the mothers in an urban resettlement colony located in East Delhi. ${ }^{22}$

Other comparable study by Coca et al (Sao Paulo, Brazil) and Kronborg et al. also reported that parity was significantly associated with position and attachment. ${ }^{14}$ However, Gupta et al from North India did not find any statistically significant association between parity, age of baby, literacy of mothers and effective breastfeeding. ${ }^{15}$ In the present study no statistical association found between education of mother and correct breast feeding technique. Fifty percentage $(50 \%)$ mothers practiced ineffective breastfeeding method at the first observation, most frequently ineffective position $(61 \%)$ and latch $(52 \%)$. Ineffective position and ineffective latch had no influence, whereas ineffective breast feeding technique showed a significant impact on time-span of breastfeeding. ${ }^{14}$

The present study indicates that preterm infants had poor attachment and suckling. Fazlur Rahim et al. found that preterm babies had poorer position, attachment and suckling as compared to full term babies. The association between gestational age and position, attachment and suckling ( $p>0.05)$ was not statistically significant. ${ }^{23} \mathrm{SP}$ da Costa et al. study mentioned that it is unclear whether poor suckling is part of their prematurity or whether it is caused by neurological problems. ${ }^{24}$
Present study indicates that a mostly (80\%) of multiparous mothers had good position and attachment, which could be the outcome of their earlier practice. Fazlur Rahim et al. reported that Primiparas women were poorer in Position (64\% against 38.5\%), Bonding (50\% against 22\%), and suckling (59\% against 22\%) in comparison to multiparas. $^{23}$

In present study major source of information regarding breast feeding technique was doctors $(57 \%)$ followed by mothers (16\%). Rukhsana Haider et al found that major providers of infant feeding information were grandmothers $(28 \%){ }^{25}$

We observed that infants with low birth weight had poor attachment and poor effective suckling. Present study was able to reveal the association between maternal and infant characteristics and positioning, attachment and effective suckling during breastfeeding. However, it might be possible to recognize other factors with bigger sample size.

\section{CONCLUSION}

Young and primipara mothers need more support and guidance for appropriate breastfeeding techniques. Every mother should be observed and counselled for proper and correct positioning and attachment of infants at the onset of breastfeeding.

\section{ACKNOWLEDGEMENTS}

Authors are thankful to ASHA workers for their support in collection of data in rural area. We are also thankful to all the mothers and children who participated in the study.

Funding: No funding sources

Conflict of interest: None declared

Ethical approval: The study was approved by the Institutional Ethics Committee

\section{REFERENCES}

1. K Park. Park's text book of preventive and social medicine, Preventive medicine in obstetrics, paediatrics and geriatrics. 2015:530-8.

2. National guidelines on infant and young child feeding. www.wcd.nic.in/nationalguidelines.pdf. Accessed on 27/04/2015.

3. Henderson P. WHO Press 20 Avenue Appia, 1211. Geneva 27, Switzerland: WHO Press, World Health Organization; 2009. Infant and young child feeding: Model chapter for textbooks for medical students and allied health professionals. Session 1- The importance of infant and young child feeding and recommended practices; pp. 5-6. Available at:whqlibdoc.who.int/publications/2009/978924159 7494_eng.pdf. 
4. World Bank. Repositioning nutrition as central to development: a strategy for large scale action. Washington DC, The World Bank, 2006 Available at:siteresources.worldbank.org/NUTRITION/./Nutri tionStrategy.pdf.

5. Jones G, Steketee RW, Black RE, Bhutta ZA, Morris SS. How many child deaths can we prevent this year? Lancet. 2003;362:65-71. Available at:www.who.int/child...health/.../lancet_child_surviv al_prevent_deaths.pdf accessed on 28.04.2015.

6. World Health Organization, Infant and young child feeding, Model chapter for textbooks for medical students and allied health professional pp 13. Available

at:whqlibdoc.who.int/publications/2009/978924159 7494_eng.pdf.

7. National Rural Health Mission. http://nrhm.gov.in/ nrhm-components/ rmnch-a/ child-healthimmunization/ child-health/ guidelines.html. Accessed on 26/04/2015.

8. Dongre AR, Deshmukh PR, Rawool AP, Garg BS. Where and how breastfeeding promotion initiatives should focus its attention? A study from rural wardha. Indian J Community Med. 2010;35:226-9.

9. Vinther T, Helsing E. Breastfeeding- how to support success: a practical guide for health workers. Copenhagen: World Health Organization, Regional Office for Europe. 1997:10-2.

10. Woolridge MW. Aetiology of sore nipples. Midwifery. 1986;2:172-6. Available at:http://www.midwiferyjournal.com/article/S02666138\%2886\%2980042-0/abstract.

11. Blair A, Cadwell K, Turner-Maffei C, Brimdyr K. The relationship between positioning, the breastfeeding dynamic, the latching process and pain in breastfeeding mothers with sore nipples. Breastfeed Rev. 2003;11:5-10.

12. Weigert EM, Giugliani ER, França MC, Oliveira LD, Bonilha A, Espírito Santo LC, et al. The influence of breastfeeding technique on the frequencies of exclusive breastfeeding and nipple trauma in the first month of lactation. J Pediatr (Rio J). 2005;81:310-6.

13. Matthews MK. Experiences of primiparous breastfeeding mothers in the first days following birth. ClinNursRes.1993;2:309-26.

14. Kronborg H, Vaeth M. How are effective breastfeeding technique and pacifier use related to breastfeeding problems and breastfeeding duration? Birth. 2009;36:34-42.

15. Gupta M, Aggarwal AK. Feasibility study of IMNCI guidelines on effective breastfeeding in a rural area of North India. Indian J Community Med. 2008;33:201-3.

16. Santo LC, de Oliveira LD, Giugliani ER. Factors associated with low incidence of exclusive breastfeeding for the first 6 months. Birth. 2007;34:212-9.

17. Sai M, Kishore S, Kumar P, Aggarwal AK. Breastfeeding knowledge and practices amongst mothers in a rural population of North India: A community-based study. J Trop Pediatr. 2009;55:183-8.

18. Essa RM, Ebrahim EM. Effect of breast milk versus therapeutic honey (Apicare) on cracked nipples' healing. Life Science Journal. 2013:10(1).

19. Mannan I, Rahman SM, Sania A, Seraji HR, Arifeen SE, Winch PJ, et al. Can early postpartum home visits by trained community health workers improve breastfeeding of newborns? J Perinatol. 2008;28:632-40.

20. Thakre SB, Thakre SS, Ughade SM, Golawar S, Thakre AD, Kale P. The breastfeeding practices: the positioning and attachment initiative among the mothers of rural Nagpur. J Clin Diagn Res. 2012;6(7):1215-8.

21. Shrivastava P, Saha I, Nandy S. A study on feeding practice of under 6 months infants attending the nutrition clinic of a tertiary care hospital of West Bengal, India. Epidemiology Biostatistics and Public Health. 2013;10:2.

22. Parashar M, Singh S, Kishore J, Patavegar BN. Breastfeeding attachment and positioning technique, practices, and knowledge of related issues among mothers in a resettlement colony of Delhi. ICAN: Infant, Child, and Adolescent. 2015;20(10):1-6.

23. Rahim F, Muhammad J, Ali S, Amir S. Breastfeeding practices in neonatal units. J Med Sci. (Peshawar, Print) 2014;22(4):159-63.

24. Costa SD, Engel-Hoek LVD, Bos AF. State of the art, sucking and swallowing in infants and diagnostic tools. J Perinatol. 2008;28:247-57.

25. Haider R, Rasheed S, Sanghvi TG, Hassan N, Pachon $\mathrm{H}$, Isla $\mathrm{S}$, et al. Available at: http://www.internationalbreastfeedingjournal.com/c ontent/5/1/21.

Cite this article as: Prajapati AC, Chandwani H, Rana $\mathrm{B}$, Sonaliya KN. A community based assessment study of positioning, attachment and suckling during breastfeeding among 0-6 months aged infants in rural area of Gandhinagar district, Gujarat, India. Int J Community Med Public Health 2016;3:1921-6. 